\title{
LA INTIMIDAD CORPORAL Y SUS BASES NEUROBIOLÓGICAS ${ }^{1}$
}

\author{
JESÚS CONILL \\ Universidad de Valencia
}

\begin{abstract}
RESUMEN: La primera parte de este estudio resalta la importancia de la intimidad para la vida humana y defiende la perspectiva biológica frente a la computacional funcionalista. Se basa en la concepción de la subjetividad corporal en Nietzsche, la intimidad corporal, sentimental y espiritual en Ortega y Gasset, y la intimidad corporal y personal en Zubiri. La segunda parte expone una selección significativa de algunos estudios sobre las bases neurobiológicas de la intimidad corporal, que superan los estériles reduccionismos: su posible sustrato neuronal (¿neurologia de la intimidad?), el cerebro como sistema seleccional, las neuronas espejo, la synestesia y la neurofenomenología. Y termina planteando el problema del poder de la intimidad, el conflicto entre ésta y la reputación.
\end{abstract}

PALABRAS CLAVE: intimidad, cuerpo, subjetividad, experiencia, libertad, persona, Nietzsche, Ortega y Gasset, Zubiri.

\section{Bodily Intimacy and its Neurobiological Foundations}

ABSTRACT: The first part of this study stresses the importance of intimacy for human life and defends the biological standpoint against the functionalist computational stance. This is based on the concept of bodily subjectivity in Nietzsche, bodily, emotional and spiritual intimacy in Ortega y Gasset, and bodily and personal intimacy in Zubiri. The second part sets forth a significant selection taken from studies on the neurobiological foundations of bodily intimacy, reaching beyond sterile reductionisms: its possible neuronal substrate (the neurology of intimacy?), the brain as selectional system, mirror neurons, synaesthesia and neurophenomenology. It ends by putting forward the problem of the power of intimacy, the conflict between this and the reputation.

KEY WORDS: intimacy, body, subjectivity, experience, freedom, personhood, Nietzsche, Ortega y Gasset, Zubiri.

\section{INTRODUCCIÓN}

La intimidad es un asunto muy serio, tal vez lo más serio del ser humano; así lo vio Laín Entralgo, para quien hablar y vivir «en serio» es vivir desde lo más íntimo ${ }^{2}$. El ámbito de lo serio en la vida humana se encuentra en la intimidad a través del ensimismamiento y por eso hablar en serio es dialogar desde la intimidad. La intimidad nos capacita para estar más allá de las farsas y acomodos en cada sociedad; es el ámbito de la sinceridad y la verdad personal, sintiendo lo que es uno en sí mismo y como persona. Sin esa condición de la

1 Este estudio se inserta en el Proyecto de Investigación Científica y Desarrollo Tecnológico FFI2013-47136-C2-1-P, financiado por el Ministerio de Economía y Competitividad, y en las actividades del grupo de investigación de excelencia PROMETEO/2009/085 de la Generalitat Valenciana.

2 Entralgo, P. L., Ser y conducta del hombre, Espasa Calpe, Madrid, 1996, pp. 495-498. 
íntima seriedad no se podría argumentar como es debido. De ahí su decisiva importancia en la vida humana y el reconocimiento que ha recibido en diversas concepciones filosóficas contemporáneas ${ }^{3}$.

A pesar de su indiscutible importancia, la intimidad ha sido interpretada habitualmente como algo exclusivamente interno e inaccesible, hasta secreto; cuando en realidad sólo se accede a ella y se la vive a partir de la corporalidad humana, de la subjetividad corporal, de la experiencia del cuerpo viviente (Leib), una experiencia repleta de vivencias y de significaciones, y que tiene la peculiaridad de ser de cada cual (mía) y se expresa en primera persona, siendo experiencia de sí mismo. Esta línea de interpretación corporal de la intimidad se ha intensificado a partir de Nietzsche y, en la tradición hispana, sin olvidar a Unamuno, desde Ortega y Gasset, hasta Zubiri y Laín Entralgo.

Ahora bien, la vivencia de la intimidad se suele reducir a la privacidad (en sentido jurídico o mental) ${ }^{4}$ y en los últimos tiempos se ha erosionado por diversas razones, sobre todo de carácter sociológico (la extimidad va asfixiando la intimidad), pero también debido a la creciente preponderancia de algunas concepciones tecnocientíficas, como el computacionismo funcionalista, que imponen una visión del ser humano en que parece esfumarse el ámbito de la intimidad. Al parecer, el computacionismo elimina la intimidad y acaba en un automatismo. Por ejemplo, las máquinas inteligentes y «espirituales», así como los cerebros digitales, diseñados por la nueva tecnología ${ }^{5}$, no serían capaces de intimidad y la anunciada «singularidad» se alcanzaría al margen de la intimidad. Por otra parte, el computacionismo aspira al automatismo y, como es sabido, la automación consiste básicamente en aplicar la automática a un proceso o a un dispositivo, siendo su pretensión sustituir en los más diversos procesos al operador humano por dispositivos mecánicos o electrónicos, que funcionan por sí solos. Con lo cual surge la pregunta de si este presunto logro, en un futuro posthumano, equivaldría a decir "por sí mismos», en el mismo sentido que la intimidad humana, tal como ahora la entendemos radicada en el cuerpo.

Porque, en principio, la intimidad es un componente de la vida humana sólo a partir de su corporalidad y no parece posible pensar la intimidad desde el punto de vista computacional, sino sólo por la vía biológica. Un buen ejemplo es el de Edelman y Tononi, que defienden la perspectiva biológica frente la computacional, posibilitando así la capacidad corporal de intimidad ${ }^{6}$. Ciertamente,

3 Por ejemplo, la importancia de lo «en serio» en la filosofía de Karl-Otto Apel radica en que la condición decisiva en el ámbito de la comunicación es la voluntad de dialogar «en serio» (im Ernst); también Tugendhat abogaba por una moral de la seriedad (Ernsthaftigkeit), en la medida en que ésta se refiere al modo de atenerse a «mí mismo» («Retraktationen», en Probleme der Ethik).

4 Vid. Gracia, D., Como arqueros al blanco, Triacastela, Madrid, 2004, pp. 120-125, y SAlles, A., "Privacidad mental y discusión neuroética», Simposio Internacional, UJICastellón, 29 de Junio, 2016.

5 Kurzweil, R., Cómo crear una mente, Lola Books, Berín, 2013.

6 Edelman, G. M. y Tononi, G., El universo de la conciencia, Crítica, Barcelona, 2005; Vid. también «Retos actuales de la neuroética», Reçerca, 13 (2013). 
la mismidad personal no depende meramente de nuestros genes, sino de las conexiones cerebrales, pero esto no implica que haya una equivalencia entre «mi cerebro» y los programas de procesamiento de la información, conforme a la trasnochada analogía entre cerebro y ordenador (computador). Más bien, hay que distinguir dos principios interpretativos del cerebro y del sistema nervioso; es decir, según Edelman y Tononi, entre la computación (el procesamiento de información mediante un algoritmo universal) y la selección biológica incluso en el orden neuronal. Sólo a partir de esta segunda vía será posible hablar de «nuestro» neocórtex, no así cuando el neocórtex fuera artificialmente digitalizado, porque sólo puede ser «nuestro» biológicamente, corporalizadamente ${ }^{7}$.

\section{SubJeTIVIdAd CORPoral (NietZsCHE)}

Las teorías tradicionales de la subjetividad han fracasado porque han estado dominadas por el esquema de la presunta autoconciencia epistémica inmediata, con lo cual la subjetividad parecía estar constituida por la autoconciencia epistémica, que consiste en "el saber inmediato que uno tiene de sí mismo, de sus propios estados conscientes» ${ }^{8}$. La vía de solución ha sido abrir el ámbito de un concepto práctico de autoconciencia, o bien contar con un nuevo sentido de la subjetividad, más allá de la conciencia, como en Nietzsche, «siguiendo el hilo conductor del cuerpo».

En la subjetividad corporal hay otros componentes, además de los lógicoreflexivos, como los impulsos y la pasión, como ya pusieron de relieve, por ejemplo, Aristóteles y Spinoza, cuya reactualización en las neurociencias no es casual ${ }^{9}$. Pero la transformación nietzscheana del pensamiento radicaliza el estudio del cuerpo llegando hasta los elementos de carácter tropológico (metafórico), lingüístico y afectivo, de la subjetividad, que son los destacados en la versión psicofisiológica del nuevo criticismo nietzscheano, en la versión de una hermenéutica genealógica.

Esta ampliación nietzscheana del criticismo kantiano descubre el carácter vital y perspectivista de una subjetividad que se vive y expresa a través de procesos de interpretación. El sujeto humano transforma impulsos en interpretaciones ${ }^{10}$.

${ }^{7}$ Lo mismo ocurre con la consciencia, que se sustenta básicamente en un proceso biológico (SEARle, J., El misterio de la conciencia, Paidós, Barcelona, 2009; Morgado, I., Cómo percibimos el mundo, Ariel, Barcelona, 2012; Fuster, J., Cerebro y libertad, Ariel, Barcelona, 2014).

8 Tugendhadt, E., Selbstbewusstsein und Selbstbestimmung, Suhrkamp, Frankfurt am Main, 1979, p. 27.

9 No debería olvidarse que el «Perì psychês» pertenece al ámbito de la Física, en el sentido aristotélico, y que se basa en una enorme cantidad de estudios biológicos; para la actualidad de Spinoza en este aspecto, vid. el estudio de Benito, P., Baruch Spinoza. Una nueva ética para la liberación humana, Biblioteca Nueva, Madrid, 2015 y Damasio, A., En busca de Spinoza. Neurobiología de la emoción y los sentimientos, Destino, Barcelona, 2011.

10 Nietzsche, F., A § 553 (Aurora, Olañeta, Barcelona, 1981). 
Se ofrece así una concepción corporal de la subjetividad humana ${ }^{11}$ : «detrás de tus pensamientos y sentimientos (...) se encuentra un soberano poderoso, un sabio desconocido -llámase sí-mismo (Selbst). En tu cuerpo habita, es tu cuerpo» ${ }^{12}$.

El desarrollo de la subjetividad corporal depende de los procesos corporales de interpretación y de invención de formas ${ }^{13}$, de una fuerza que actúa continuamente interpretando en todos los procesos orgánicos: «La voluntad de poder interpreta» ${ }^{14}$. Y este "factum último» de la voluntad de poder como fuerza interpretadora originaria sería, según Nietzsche, la libertad: «El ansia más terrible y más fundamental del hombre, su impulso en busca de poder -a este impulso se le llama "libertad" ${ }^{15}$.

Este trasfondo dinámico de la intimidad corporal humana está vinculado a la conciencia moral de obligación, según el análisis hermenéutico-genealógico de Nietzsche ${ }^{16}$. Desde su perspectiva, el origen de la obligación radica en un "instintivo crear formas» (instintives Formen-schaffen), en el que late un «quantum de libertad», un «instinto de libertad», "encarcelado en lo interior» (ins Innere eingekerkerte), que acaba por descargarse contra «sí mismo» y que constituye el inicio de la "mala conciencia» (das schlechte Gewissen). El origen [Ursprung] de la mala conciencia está en la «interiorización del hombre» (Verinnerlichung des Menschen $)^{17}$, en un "sí mismo», en la intimidad corporal.

La misma fuerza que actúa en la instintiva creación de formas es la que ahora, en un mundo «interior (innerlich)», «en el "laberinto del pecho» (expresado con palabras de Goethe), se crea la "mala conciencia» y construye ideales. Se trata de aquel "instinto de la libertad", que Nietzsche denomina "voluntad de poder"; sólo que ahora esa fuerza "conformadora" (formbildende)» se desahoga sobre el hombre mismo y potencia la capacidad de «darse forma a sí mismo» ${ }^{18}$.

Esta genealogía hermenéutica de Nietzsche incorporó el componente neurológico ${ }^{19}$. Las experiencias se comprenden como «fenómenos cerebrales» ${ }^{20} \mathrm{y}$ las funciones superiores del espíritu se conectan con procesos orgánicos en los que el cerebro ejerce su peculiar función ${ }^{21}$. Pero Nietzsche no cedió al re-

11 Conill, J., «La subjetividad desde el cuerpo en Nietzsche. Una fuente de inspiración del pensamiento español contemporáneo», Quaderns de Filosofia, II, nº 1 (2015), pp. 61-78.

12 Nietzsche, F., Así habló Zaratustra, Alianza, Madrid, 1984 (12 a ed.), "De los despreciadores del cuerpo", pp. 60ss.

13 Nietzsche, F., Fragmentos póstumos (FP), Tecnos, Madrid, 2010, III, 830, 38 [10]; III, 533, 25 [463]; III, 882, 42 [3].

14 Nietzsche, F., FP IV (Tecnos, Madrid, 2006), 122, 2 [148].

15 Nietzsche, F., FP IV, 48, 1 [33].

16 Vid. Nietzsche, F., La genealogía de la moral, Alianza, Madrid, 1978, II, 17 y 18; Korsgaard, C. M. (Las fuentes de la normatividad, Unam, México, 2000, p. 17) entiende que la ética moderna de la autonomía es una ética de la [auto]obligación.

17 Nietzsche, F., La genealogía de la moral, II, 16.

18 Ibíd., II, 18.

19 Vid. Olivier, A., «Nietzsche and Neurology», Nietzsche-Studien 32 (2003), pp. 124-141.

20 KSA IX, 559: 11[309]; FP II, 826.

21 KSA XI, 106: 25 [356], FP III, 515; KSA XI, 157: 26 [35]; FP III, 547. 
duccionismo: «No es el cerebro el que piensa ${ }^{22}$, sino que somos «nosotros los que pensamos» ${ }^{23}$. «Aquí se presupone que el entero organismo piensa, que todas las formaciones orgánicas tienen parte en el pensar, sentir, querer - por consiguiente, que el cerebro es sólo un enorme aparato de centralización ${ }^{24}$. «El sistema nervioso y el cerebro son un sistema de dirección y un aparato de centralización de innumerables espíritus individuales de distinto rango ${ }^{25}$.

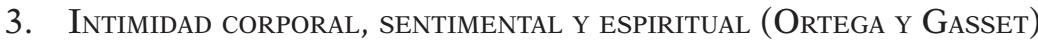

La noción orteguiana de la intimidad corporal proporciona una concepción de la intimidad que no cabe entender como una cosa o un objeto, ni es accesible por introspección subjetivista, sino como la "perspectiva» de una «realidad ejecutiva ${ }^{26}$. Por tanto, su concepción de la intimidad permite superar el cosismo, el objetivismo y el subjetivismo, a partir de una experiencia primordial del cuerpo humano. Para mostrarlo, Ortega recurre a la diferencia real (vital) que existe entre el significado del verbo en primera persona y su significado en tercera persona $^{27}$; una diferencia que equivale a la existente entre las perspectivas de primera y tercera persona, que sigue siendo tratada por actuales concepciones filosóficas y cuya base neurobiológica aportarían algunas concepciones neurocientíficas ${ }^{28}$.

La concepción corporeizada de la intimidad y de la subjetividad que presenta Ortega está conectada desde su raíz con la formación de los pronombres personales y la creación de metáforas, lo cual tiene también una renovada actualidad en algunos estudios neurocientíficos contemporáneos ${ }^{29}$. Al parecer, el ámbito de la intimidad empezó a expresarse diciendo «mi cuerpo», «mi corazón», «mi pecho»; de tal modo que «la formación de los pronombres personales relata la historia» de los diversos aspectos de la intimidad, en la que «el

22 KSA VII, 598: 27 [37]; FP I, 472.

23 KSA VII, 610: 27 [77]; FP I, 480.

24 KSA XI, 279-280: 27 [19]; FP III, 622.

25 KSA, XI, 157: 26, [36]; FP III, 547.

26 Conill, J., «La intimidad corporal en la filosofía de Ortega y Gasset», Isegoría, n ${ }^{\circ} 53$ (2015), pp. 491-513.

27 Repárese en la fecha (1914) del escrito de José Ortega y Gasset, «Ensayo de estética a manera de prólogo» (1914), Obras completas (O.C.), Taurus, Madrid, 2004-2010, I, pp. 664680.

28 Por ejemplo, la fenomenología, la neurofenomenología, la neurociencia de primera persona (vid. Gallagher, S. y Zahavi, D., La mente fenomenológica, Alianza, Madrid, 2013; VARELA, F., «Neurophenomenology. A methodological remedy for the hard problem», Journal of Consciousness Studies, 1996, 3(4), 330-349; VARGAS, E. et alii, «Neurofenomenología del tiempo según F. Varela», Actas Españolas de Psiquiatría, 2013, 41(4), 253-262; Northoff, G. y Heinzel, A., «First-person neuroscience: a new mythological approach for linking mental and neuronal states», Philosophy, Ethics, and Humanities in Medicine 1 (1): 3).

29 Ramachandran, V. S. y HubBard, E. M. han destacado precisamente este punto, al que aludiremos más tarde («Synaesthesia - A Window into Perception, thought an Language», Journal of Consciousness Studies, 8, Nr. 12, 2001, 3-34). 
pronombre posesivo precede al personal $»^{30}$, porque empezamos a conocernos por las cosas que nos pertenecen: lo «mío» sería anterior al «yo» en el proceso por el que se forma la "noción corporal del sujeto» ${ }^{31}$.

Para comprender la intimidad, según Ortega, hay que analizar sus tres aspectos: el corporal, el sentimental y desiderativo, y el espiritual (o mental) ${ }^{32}$. Pero la clave última de la intimidad corporal radica en el modo de comprender el cuerpo humano como cuerpo viviente (Leib), en el que no todo lo que sucede depende de nosotros (se piensa, se quiere) ${ }^{33}$, y cuya conceptuación goza ya de una acreditada tradición desde Nietzsche y la fenomenología, hasta la hermenéutica y antropología contemporánea. El trasfondo de la intimidad está en el cuerpo, no entendido en su especie «mineral» (los elementos químicos de que se compone), sino como «carne ${ }^{34}$, porque «lo interno de la carne» es la «intimidad» vital que se presenta y expresa en el cuerpo humano; pero que no se identifica con lo objetivable en las ciencias naturales, porque fenomenizar no equivale a objetivar, ya que cuando experienciamos el cuerpo humano lo sentimos cargado de «alusiones a una intimidad» y por eso no basta con objetivarlo sino que hay que «interpretarlo».

\section{INTIMIDAD CORPORAL Y PERSONAL (ZUBIRI)}

De gran relieve es la aportación de Zubiri, al radicalizar la concepción corporal de la intimidad, añadiéndole su carácter personal. «No todo lo real posee intimidad; esto sólo se da (...) en las realidades humanas. Las cosas materiales carecen de intimidad; pero poseen interioridad $»^{35}$. Por tanto, en el pensamiento zubiriano, la intimidad sirve para distinguir entre naturaleza (lo que una cosa es) y persona (en qué consiste el «quién», de quién es aquello que la cosa es) ${ }^{36}$. Sólo el hombre es capaz de entrar en su intimidad personal y esta experiencia lo coloca en un puesto especial dentro del $\operatorname{cosmos}^{37}$, ya que se siente impelido a

30 También en este punto hay aportaciones actuales de las neurociencias (RAMACHANDRAN, V. S.) y la neurofenomenología (VARela, F.; Gallagher, S. y ZahaVI, D.), que han distinguido entre el sentido primordial de propiedad del propio cuerpo y el de agencia, como se verá más tarde.

31 «Las dos grandes metáforas (En el segundo centenario del nacimiento de Kant)» (1924), O.C. II, pp. 505-517.

32 «Vitalidad, alma, espíritu» (1925), O.C., II, pp. 566-592.

33 Vid. Lichtenberg, G., Vermischte Schriften, 1867, Bd. I, 99; Nietzsche, F., Más allá del bien y del mal, § 16, 17 y 54; Genealogía de la moral, I, 13; STIngelin, M., «Sprachphilosophie», en H. Ottmann (Hrsg.), Nietzsche Handbuch, Metzler, Stuttgart, 2000, pp. 425-426.

34 «Sobre la expresión, fenómeno cósmico» (1925), O.C., II, pp. 681-695.

35 Zubiri, X., Sobre la esencia. Nueva edición, Alianza/Fundación Xavier Zubiri, Madrid, p. 493.

36 Zubiri, X., «Sobre el problema de la filosofía» (1933), en Sobre el problema de la filosofía y otros escritos (1932-1944), Alianza/Fundación Xavier Zubiri, Madrid, 2002, pp. 17-124.

37 Ibíd., p. 118. 
descubrir la estructura de su vida personal. Desde esta experiencia de la intimidad personal es desde donde cabe superar la cosmovisión naturalista, heredada de la filosofía griega clásica, y abrir un nuevo horizonte. Pero la posterior tendencia a defender la irreductibilidad de la persona a la naturaleza (por ejemplo, desde Kant hasta Heidegger), según Zubiri, no debería llevar (necesariamente) a renunciar a la intimidad corporal, porque el momento del «me» y del «mi» pertenece al cuerpo (se da en el cuerpo humano). Pues, desde su intimidad corporal, el hombre existe (vive) como persona. Su cuerpo está personalizado, es personal: persona corporal.

Esta intimidad humana, según Zubiri, «se expresa en la triple versión del me, del mí y del yo». El «mí» no ha de confundirse con el sujeto, ni con la conciencia, ni es lo más oculto, sino el modo de estar afectado con carácter de intimidad. Pues el color de la cara, el tono de la voz, la cabellera, todo forma parte de la intimidad, porque todo es «mío» (mi color, mi cara, mi expresión). Por eso, la intimidad no puede reducirse a una cuestión psicológica, sino que es la «vivencia metafísica» de la propia "pertenencia» personal ${ }^{38}$, en la que me siento y me vivo a mí mismo construyendo una trama vital, y cuyo último aspecto será la «libertad incorporada» ${ }^{39}$.

Igual que la intimidad no se reduce a «interioridad», tampoco se asimila a la «mismidad», sino que se sitúa en el dinamismo de la «suidad», de la personalización de la vida ${ }^{40}$. Sin intimidad no hay personalización. Más allá de la mismidad biológica se pone en marcha un proyecto que opera por apropiación y apoderamiento de posibilidades. Es la innovación personal de la libertad ${ }^{41}$.

Como en Ortega, también los sentimientos pertenecen al orden de la intimi$\mathrm{dad}^{42}$. La intimidad es el momento que tienen todas las cualidades del hombre por el hecho de ser suyas (como en los ejemplos antes aludidos: color de la cara, tono de voz). La cenestesia es la que me da mi realidad como intimidad y por la que accedo a ella, aprehendiéndome como estando en mí $^{43}$. Y es de este fondo de mi propia realidad, en la que me soy yo mismo, desde donde emerge la «voz de la conciencia» ${ }^{44}$. La intimidad es una presencia dinámica de autoconocimiento experiencial, en la que me aprehendo a mí mismo como realidad mía, siendo permanentemente el mismo, aunque no lo mismo. Ahora bien, como la intimidad está siempre corporalmente encarnada, según Laín Entralgo,

38 Zubiri, X., Sobre el hombre, Alianza/Sociedad de Estudios y Publicaciones, Madrid, 1986, pp. 133-135.

39 Ibid., pp. 150 y 152.

40 Zubiri, X., Estructura dinámica de la realidad, Alianza/Fundación Xavier Zubiri, 1989, p. 205.

41 Ibid., p. 249 y 250.

42 ZubIRI, X., Sobre el sentimiento y la volición, Alianza/Fundación Xavier Zubiri, 1992, p. 331 .

43 ZubIRI, X., Inteligencia sentiente, Madrid, Alianza/Sociedad de Estudios y Publicaciones, 1980, pp. 108-109.

44 Zubiri, X., El hombre y Dios. Nueva edición, Alianza/Fundación Xavier Zubiri, Madrid, pp. 106-109. 
su comprensión es una tarea complementaria para la filosofía y la neurofisiología, porque se trata del «modo de ser de los actos psicorgánicos en el cual y con el cual mi vida se me hace real y verdaderamente propia», es decir, "mía»"

Esta línea de Zubiri y Laín Entralgo aporta una interpretación de la intimidad basada en la investigación científica, pero sin dejarse llevar por la deriva positivista. De lo que se trata a continuación es de reactualizar esta concepción filosófica de la intimidad corporal, atendiendo al actual desarrollo de las neurociencias.

\section{Bases NeURobiológICAS DE LA INTIMIDAD CORPORAL}

Ya en el siglo vi a.C. Alcmeón de Crotona, médico y filósofo de la naturaleza, descubrió por medio de sus disecciones en animales que el cerebro es el centro de nuestras sensaciones ${ }^{46}$. Y, de modo muy significativo, Hipócrates destacó que el cerebro es el «mensajero» (diángellos) de la actividad psíquica, «nuestro intérprete» (hermeneus) ${ }^{47}$. Desde antiguo, pues, hay una línea de pensamiento filosófico y científico que ha destacado el papel central del cerebro en la vida anímica. Pero lo que ahora interesa no es rastrear por la historia de la neurociencia $^{48}$, sino seleccionar algunos estudios en el panorama actual que ofrecen aspectos relevantes sobre el sustrato neuronal de la intimidad humana.

\subsection{El sustrato neuronal de la intimidad}

Comencemos por una de las aportaciones más características de dicho sustrato neuronal. Según Edelman y Tononi ${ }^{49}$, el mundo de la experiencia subjetiva no es un objeto, ni un lugar, ni una cosa, ni una propiedad, sino un proceso de integración neuronal, es decir, una integración procesual; pero «ninguna descripción o explicación científica puede sustituir al fenómeno real» de la experiencia ${ }^{50}$. Por tanto, no somos sólo lo que describimos científicamente y, por tanto, tampoco la intimidad es lo que podamos describir científicamente de

45 Laín, P., «La intimidad del hombre», Biblioteca Virtual Miguel de Cervantes (http:// www.cervantesvirtual.com).

46 Cubells, F., Los filósofos presocráticos (1956), Facultad de Teología San Vicente Ferrer, Valencia, 1979.

47 Laín, P., Medicina hipocrática, Revista de Occidente, Madrid, 1970, p. 171; «Sobre la enfermedad sagrada», 17-19, Tratados hipocráticos I, Gredos, Madrid, 1983, pp. 415-417 (citado por José Ramón Amor Pan, Bioética y Neurociencias, Institut Borja de Bioética, Universidad Raimon Llull, 2015, p. 24).

48 Vid. Blanco, C., Historia de la neurociencia, Biblioteca Nueva, Madrid, 2014; RodríGuez VAlLs, F. et alii (eds.), Asalto a lo mental, Biblioteca Nueva, Madrid, 2011; El sujeto emocional, Thémata, Sevilla, 2015.

49 Edelman, G. M. y Tononi, G., El universo de la conciencia, Crítica, Barcelona, 2005, pp. 145, 177, 255; Javier Monserrat, "G.M. Edelman y su antropología neurológica», Pensamiento, 234, 2006, pp. 441-470.

50 Edelman, G. M. y Tononi, G., El universo de la conciencia, pp. 24, 191 ss., 264-265. 
ella. No obstante, hay que investigar qué procesos neuronales explican las propiedades de la intimidad corporal que experienciamos.

Aunque estos autores siguen hablando de privacidad e interioridad, sería mejor reconvertir estos términos en el de intimidad. Con él se expresan más adecuadamente los rasgos que ya provienen de ciertas características del cerebro y que constituyen las bases de la intimidad: 1) que «no es una computadora» ${ }^{51}$, 2) que, aunque gran parte de sus funciones pueden automatizarse, sin embargo no es posible automatizar la "propia elección consciente» ${ }^{52}$; 3) que no hay dos cerebros iguales, sino que cada cerebro es único, debido a la diversidad del historial experiencial de cada uno ${ }^{53}$; 4) que el cerebro funciona sin «reglas lógicas» de un código programado, a partir de su interacción con el cuerpo y el entorno, y a través de la «reentrada», que es un proceso de selección neuronal de orden superior (donde el seleccionismo corporal se impone a las pretensiones del computacionismo).

La intimidad tiene a su base un cerebro que funciona 1) conforme a una "selección somática», que estos autores comparan con el sistema inmunitario $^{54}$, 2) conforme a una «integración neuronal» y 3) conforme a "valores» (no meras instrucciones, ni categorías), que tienen que ver más con «señales» ${ }^{55}$. Por tanto, los procesos neuronales se convierten en intérpretes de señales, porque éstas «no representan», sino que son ambiguas (dependen del contexto), y «no existe ningún mensaje precodificado en la señal» ${ }^{56}$; emerge así una capacidad de recrear, imaginar y elegir respuestas ${ }^{57}$. He aquí la base neurofisiológica de la experiencia subjetiva, de la intimidad corporal, incluso de carácter "personal».

Un ejemplo ya clásico es el de la experiencia subjetiva de las cualidades llamadas «qualia», en la que se producen unas «discriminaciones» (unos discernimientos) que tienen un «significado» ${ }^{58}$, para el que las neuronas son necesarias pero no suficientes; entre ellas se encuentran las del propio cuerpo, las del "proto yo $»^{59}$ y la intimidad ${ }^{60}$. Así pues, la intimidad surge desde el cuerpo, está corporeizada, y nos capacita para integrar información e interpretarla. De hecho, estos autores entienden que "la información es un concepto biológico» ${ }^{61}$ y que constituye «el logro más trascendental de la evolución», porque es un

51 Ibíd., pp. 61, 118 ss., 255 ss.

52 Ibid., p. 39.

53 Ibid., pp. 61-62, 105.

54 Ibid., pp. 106-107.

55 Ibid., pp. 110 y 112-117.

56 Ibíd., p. 119.

57 Ibíd., pp. 120, 123, 126, 134, 135.

$58 \quad$ Ibíd., p. 204.

59 Vid. Damasio, A., El error de Descartes, Crítica, Barcelona, 2010; Y el cerebro creó al hombre [Self Comes to Mind], Destino, Barcelona, 2010.

60 Edelman y Tononi (p. 220) remiten a W. James, quien cita a M.V. Egger, La parole intérieure, París, 1881.

61 Edelman, G. M. y Tononi, G., El universo de la conciencia, p. 254; a mi juicio, más acertado sería calificarlo de «biohermenéutico». 
«salto» que adquiere incluso la posibilidad de la «subjetividad», dado que es información «para alguien» ${ }^{62}$.

Por consiguiente, el cerebro no es una máquina, ni una especie de computador, sino un «sistema seleccional», que opera por un proceso de selección somática; de ahí que cada cerebro sea único e imprevisible. Es la selección, y no la lógica, lo que subyace al reconocimiento de patrones y al pensamiento con metáforas ${ }^{63}$. Este modo de entender y de «mirar el cerebro desde dentro» por parte de la investigación científica es «coherente con los hechos de la individualidad y subjetividad humanas ${ }^{64}$, por consiguiente, con el factum experiencial de la intimidad corporal. He aquí un reconocimiento científico del dominio de la subjetividad y de la intimidad humana, es decir, de las capacidades que nos proporcionan un margen de libertad. El estudio de las bases neurobiológicas puede convivir «en provechosa simbiosis» con la experiencia del significado en el ámbito de la intimidad corporal ${ }^{65}$.

No podemos dejar de mencionar en esta selección sobre las bases neurobiológicas de la intimidad y la experiencia subjetiva en primera persona a Jürgen Habermas y Katinka Evers ${ }^{66}$. Y también otros han defendido la realidad de la intimidad, por ejemplo, basándose en la neuroplasticidad del cerebro, que se ha considerado la base biológica de la «apertura» del hombre, de la intimidad y la libertad ${ }^{67}$, así como la base neurofisiológica del «nosotros mismos» ${ }^{68}$. Pero en los últimos tiempos ha adquirido especial relevancia el estudio de las neuronas espejo.

\subsection{Neuronas espejo}

Aunque haya quien piense que está decayendo la importancia de las neuronas espejo o que no son tan decisivas como había parecido ${ }^{69}$, su descubrimiento ha tenido un especial significado para comprender el ámbito de la intimidad corporal.

$62 \quad$ Ibíd., pp. 254 y 255.

$63 \quad$ Ibid. pp. 256 y 257.

${ }^{64}$ Ibid., pp. 259 y 261.

65 Ibid., p. 264; también Patricia S. Churchland, «Human Dignity from a Neurophilosophical Perspective», en Human Dignity and Bioethics, President's Council on Bioethics, Washington, 2008, pp. 99-121.

${ }^{66}$ Así me lo indica con razón Andrés Richart en sus comentarios al trabajo en el grupo de investigación. Vid. Habermas, J., Entre naturalismo y religión, Paidós, Barcelona, 2006; Philosophische Texte, Suhrkamp, Frankfurt a.M., 2009, vol. V; y Evers, K, Neuroética, Katz, Buenos Aires, 2010.

67 Diosdado, C., «La plasticidad cerebral y la búsqueda del sentido de la propia existencia», en Rodríguez Valls , F. et alii (eds.), Asalto a lo mental, Biblioteca Nueva, Madrid, 2011, pp. 45-59.

68 Llinás, R., El cerebro y el mito del yo, Belacqua, Barcelona, 2003, p. 15.

69 Vid. Wolf, C., «Debate en torno a las neuronas espejo», Mente y cerebro 65, 2014, pp. 64-67 (citado por Juan Arana, La conciencia inexplicada, Biblioteca Nueva, Madrid, 2015); Patricia Churchland, El cerebro moral, Paidós, Barcelona, p. 152-179. 
Las neuronas espejo favorecen la detección de los estados mentales de los demás a través de un proceso de simulación y brindan una explicación neurofisiológica de la cognición e interacción social, al ayudar a reconocer las acciones, las motivaciones y las intenciones de otros ${ }^{70}$. Comprendemos a los otros simulando la situación en que se encuentran y las neuronas espejo explicarían ese proceso de simulación que lleva a cabo el cerebro de modo irreflexivo ${ }^{71}$. Aunque tampoco en este punto es aceptable ningún reduccionismo neurocéntrico $^{72}$, sino que hace falta mantener una actitud crítica en el desarrollo de la neurociencia.

Las neuronas espejo aportan la base neurofisiológica del vínculo entre ver y actuar, entre percepción y acción, en un proceso unificado en el cerebro. En las neuronas espejo se sustentan la simulación, la imitación, la comprensión directa, el reconocimiento. Con lo cual se refuerza un «modelo ideomotor» de la acción humana, a diferencia del modelo sensorial y motor, que entendía la acción con el esquema estímulo-respuesta ${ }^{73}$. En el nuevo modelo ideomotor la capacidad de imitar funciona por contagio emocional ${ }^{74}$, pues cuando imitamos "compartimos». La intimidad corporeizada está a la base de la intersubjetividad, con lo cual en las neuronas espejo encontramos una raíz biológica del «nosotros» (frente a la interpretación individualista de las relaciones humanas). Comprender a los otros mediante la simulación (consciente o inconsciente) «es como si el otro se transformara en otro yo" (Gallese y Iacoboni), o bien "es como si la intención del otro habitara mi cuerpo, y la mía, el del otro» (Merleau-Ponty) ${ }^{75}$. Las neuronas espejo no sólo facilitan la comunicación, el reconocimiento y la comprensión, sino que permiten compartir la intimidad.

En la activación de las neuronas espejo se produce una experiencia significativa de los demás y de nosotros mismos, en la que comprendemos de un

70 Iacoboni, M., Las neuronas espejo, Katz, Madrid, 2009, pp. 15 y 17; Amor Pan, J. R., Bioética y neurociencias, pp. 48-52.

71 Gallese, V. y Goldman, A., "Mirror neurons and the simulation-theroy of mindreading», Tends in Cognitive Sciences, 2 (1998), 493-501; GARCíA, E., «Neuropsicología del comportamiento moral. Neuronas espejo, funciones ejecutivas y ética universal», en DE LA Torre, J. (ed.), Neurociencia neuroética y bioética, Universidad Comillas, Madrid, 2014, pp. 43-75, especialmente 55 y 56.

72 Amor, J. R., Bioética y neurociencias, p. 54-57; Fuster, J., Cerebro y libertad, Ariel, Barcelona, 2014, p. 124.

73 La noción de «acción ideomotora» fue defendida por Hermann Lotze (1852) y por William James (1890), y, a su modo, por Ortega y Gasset con la distinción entre «ideoma» y «draoma».

${ }^{74} \mathrm{Al}$ que ya se refirió Teodoro Lipps (Los problemas fundamentales de la Ética, Daniel Jorro, Madrid, 1926). Vid. HatField, E. et alii, Emotional Contagion, Cambridge University Press, Editions de la Maison des Sciences de l’Homme, 1994.

75 Vid. Gallese, V. et alii, "Intentional attunement: Mirror neurons and the neural underpinnings of interpersonal relations», Brain Research, 1079, 2006, pp. 15-24 y MerLeAuPonty, Fenomenología de la percepción (citados por Icaboni, M., Las neuronas espejo, Katz, Madrid, 2009, p. 81 y también por Rizzolatti, G. y Sinigaglia, C., Las neuronas espejo, Paidós, Barcelona, 2006, p. 130). 
modo pragmático, preconceptual y prelingüístico: «el cerebro que actúa es un cerebro que comprende» ${ }^{76}$. El sistema de las neuronas espejo parece decisivo en el surgimiento de la experiencia común, que está en el origen de nuestra capacidad de actuar como sujetos, compartiendo las acciones y las emociones. Esto muestra el profundo arraigo de lo que nos une en un «nosotros» ${ }^{77}$, más allá de las diferencias culturales, en una potencial experiencia intersubjetiva a partir de la vivencia de la intimidad corporal y su base neurofisiológica. En esta experiencia comprensiva del significado de la acción (ya sea realizada u observada) se da una implicación íntima en primera persona ${ }^{78}$. No obstante, aunque la comprensión inmediata (en primera persona) de las emociones de los demás es un prerrequisito del comportamiento empático, no es todavía suficiente para experimentar una implicación empática con respecto a otra persona. Es decir, el reconocimiento del estado emotivo ajeno es inmediato, debido al mecanismo de las neuronas espejo; pero dicha percepción no determina la participación empática y por eso no nos vemos inducidos automáticamente a sentir compasión. Así, por ejemplo, el reconocimiento del dolor no implica sentir compasión: «la compasión depende de factores distintos al reconocimiento del dolor ${ }^{79}$.

En suma, según Iacoboni ${ }^{80}$, mediante la actividad de las neuronas espejo se va conformando el espacio de la intimidad y la intersubjetividad: en los demás nos vemos a nosotros mismos y se va formando un sentido del sí mismo. El autorreconocimiento y la imitación van unidas, sobre la base de las neuronas espejo y las interacciones imitativas. Cuando miramos a los otros, nos encontramos tanto con ellos como con nosotros mismos. Se trata de un vínculo entre el entorno y la conciencia del propio sí mismo.

\section{3. ¿Neurología de la intimidad?}

Una interpretación especial de las neuronas espejo es la que ofrece Ramachandran en su propuesta de una neurología de la autoconciencia ${ }^{81}$, que sería aplicable en parte al ámbito de la intimidad. Tanto en la «conciencia del otro» como en lo que llamamos «autoconciencia» interviene el sistema específico de las neuronas espejo. Ese ámbito del sí mismo tiene un sentido de unidad, de continuidad temporal y de control de la acción, pero está radicado en el cuerpo y centrado en el cerebro.

$\mathrm{Al}$ conjunto de estas neuronas que se activan con la misma intensidad cuando se está actuando (por ejemplo, cuando se siente dolor) que cuando se está

76 Rizzolatti, G. y Sinigaglia, C., Las neuronas espejo, p. 13.

77 Ibid., p. 14.

$78 \quad$ Ibid., p. 137.

79 Ibíd., pp. 182-183. Vid. También Evers, K., «Can We Be Epigenetically Proactive?», en Metzinger, T. \& Windt, J.M. (Eds.), Open MIND: 13(T) (www.open-mind.net), p. 5.

80 ICABONI, M., Las neuronas espejo, p. 25.

81 RamachandRan, V. S., «La neurología de la autoconciencia», Rebelión, 14-01-2007, pp. 1-4. 
observando (que otro siente dolor), Ramachandran las llama «neuronas de empatía» o "neuronas de Dalai Lama», porque parece que permiten rebasar la diferencia entre sí mismo y los demás, por tanto capacitan para una intimidad corporal, abierta, típicamente («quintaesencialmente») humana. Ésta sería asimismo la base neuronal de la empatía, del aprendizaje por imitación y de la transmisión cultural.

Según Ramachandran, una de las capacidades nuevas que han emergido en el proceso evolutivo, y que han posibilitado las neuronas espejo, ha sido la capacidad de metaforizar (transversalizando el aspecto perceptivo y el motor) y de «reflexionar» sobre las propias acciones y el propio cuerpo. La autoconciencia y el ámbito de la intimidad se sustentan en las neuronas espejo, que capacitan para mirarse a sí mismo; los mecanismos de estas neuronas sirven tanto para adoptar el punto de vita del otro como para ser capaces de volverse hacia el interior de uno mismo y tener sentido de sí mismo ${ }^{82}$. Las neuronas espejo estarían probando que los dos aspectos del yo (la intimidad y la reciprocidad) son complementarios y se basan en el mismo tipo de mecanismo neural.

\subsection{Intimidad y Sinestesia}

Otra de las propuestas en relación con las bases neurobiológicas de la intimidad es el estudio de la «sinestesia» ${ }^{83}$. El término es una combinación de «syn» $\mathrm{y}$ "aísthesis». En biología significa una sensación que se produce en una parte el cuerpo a consecuencia de un estímulo en otra parte de él. En psicología, una imagen o sensación subjetiva, propia de un sentido, determinada por otra sensación que afecta a un sentido diferente.

La sinestesia es un fenómeno - al parecer, hereditario- del que ya se percató Francis Galton en el siglo XIX y que se entiende como un "cruce de sentidos»; por ejemplo, percibir un color al oír una nota musical o en conexión con un número. En el contexto actual de las neurociencias, ha sido Ramachandran quien ha defendido que estamos ante un fenómeno perceptivo genuino, causado por la «hiperconectividad» cerebral, mediante la «conexión cruzada» o la «activación cruzada» en el giro fusiforme y en el giro angular ${ }^{84}$; un fenómeno sensorial con base neuronal que contribuye a comprender dinamismos como la metáfora ${ }^{85}$ y con ello, a mi juicio, a crear el ámbito de la intimidad ${ }^{86}$. La

82 Ramachandran considera que la presunta prueba del espejo de Gallup (el sujeto se quita una mancha de pintura de la cara mirándose en el espejo) no es una prueba adecuada de la autoconciencia (p. 3).

83 Ramachandran, V. S. and Hubbard, E. M., «Synaesthesia - A Window Into Perception, Thought and Language», Journal of Consciousness Studies, 8, No. 12, 2001, pp. 3-34.

84 Los términos usados por Ramachandran son «cross-wiring» $\mathrm{y}$ «cross-activation».

85 Ramachandran, V. S., The Emerging Mind, London, Profile Books, 2003; Ramachandran, V. S. and Hubbard, E. M., "Synaesthesia - A Window Into Perception, Thought and Language», Journal of Consciousness Studies, 8, No. 12, 2001, pp. 3-34.

86 Recuérdese lo expuesto en el contexto referido a la intimidad corporal en Ortega y Gasset. 
metáfora llega a ser posible al mezclar — conectar - cosas que de entrada no tienen nada que ver, es decir, creando un nuevo espacio vital, una experiencia innovadora.

Como el cruce de sentidos tiene a su base un cruce de percepciones y de conexiones cerebrales, Juan Miguel Pomar y Belén Aranda interpretan que la estructura cerebral que investiga Ramachandran parece indicar que «en cierto grado todos somos sinéstetas ${ }^{87}$, en la medida en que somos capaces de gestar metáforas mediante cruces perceptivos con base en conexiones cerebrales. Habría una «hiperconectvidad» o «activación cruzada» en el cerebro, que es la base neural que posibilita el mundo humano del sentido (poesía, música, arte, abstracciones).

Basado en sus investigaciones, Ramachandran defiende una sinestesia sensorial-motora, con el apoyo de las neuronas espejo. Como hemos visto, se trata de neuronas que se activan no sólo cuando se ejecutan las acciones sino cuando se observa que otro las realiza. Cabe, pues, entender que el sistema neuronal de las neuronas espejo funciona como un «simulador interno» de la acción, por tanto, la sinestesia y su vinculación con las neuronas espejo contribuirían también al estudio de las bases neurobiológicas del ámbito de la intimidad.

Ramachandran no sólo relaciona la sinestesia con el ámbito de la percepción y del pensamiento, ofreciendo una base para comprender el dinamismo metaforizador, sino que concluye con una teoría del origen y evolución del lenguaje, basada también en la sinestesia y en conexión con los gestos ${ }^{88}$. De hecho, el lenguaje ordinario está lleno de metáforas sinestésicas, de ahí que sea de interés conocer la conexión entre la sinestesia, la metáfora y la creatividad; pues parece que la sinestesia es más común entre artistas, poetas, novelistas y gente creativa en general.

Otro de los «hallazgos de las neurociencias» que presenta Ramchandran es la «relevancia» de su modelo de «hiperconectividad» — basado en procesos neurales- para los «aspectos subjetivos de la conciencia tales como las imágenes y los qualia», que considera ejemplos paradigmáticos de «estados mentales internos ${ }^{89}$, en definitiva, de la intimidad corporal. En este contexto son significativos algunos experimentos neurocientíficos que aportan datos sobre el sentido de «pertenencia» como una función del cerebro ${ }^{90}$, es decir, sobre una

87 Pomar, J M. y Aranda, B., «Sinestesia y evolución del lenguaje» (http://www.ugr.es). ¿No sería mejor decir «sinestetas»?

88 Ramachandran, V. S. and Hubbard, E. M., «Synaesthesia - A Window Into Perception, Thought and Language», Journal of Consciousness Studies, 8, No. 12, 2001, pp. 28-29.

${ }^{89}$ Ibid., p. 30.

90 Ramachandran, V. S., «Self-awareness: The last frontier. Edge The Third Culture», 2009, edge.org/3rd_culture/rama08/rama08_index.html/ (citado por Fernando Ruiz Rey, «Libre albedrío y neurociencias. Segunda parte. Hallazgos de las neurociencias», psiquiatría. com. 2009, 13(3)). Precisamente la neurofenomenología, como veremos a continuación, ha destacado la diferencia entre el sentido de propiedad y el de agencia al sentir el propio cuerpo. Y ya aludimos al sentido primordial de propiedad del propio cuerpo en el contexto orteguiano. 
especial experiencia subjetiva y personal, que no queda reducida a una causalidad físico-química. Son dos perspectivas complementarias para comprender la realidad personal a partir de su facticidad corporal, en la que acontece la experiencia de la intimidad.

\subsection{Neurofenomenología e intimidad}

Como hemos anticipado, la propia neurofenomenología pone de relieve la distinción experiencial entre el sentido de la agencia que tengo de una acción mía y el sentido de propiedad que siento de mi cuerpo y su movimiento ${ }^{91}$. Por ejemplo, en una acción involuntaria, si alguien me empuja, siento que es mi cuerpo el que se está moviendo, es mi movimiento, no el de otro; así que tengo experiencia de propiedad del movimiento, pero no experiencia de agencia del movimiento. Tengo experiencia del movimiento como ocurriendo en mí (sentido de propiedad), pero no como causado por mí (no hay sentido de agencia). "Tanto el sentido de agencia como el sentido de propiedad (lo que los fenomenólogos llaman un sentido de "ser mío» [mineness]) son experiencias fenoménicas de primer orden, pre-reflexivas» ${ }^{92}$. «Empleando esta distinción, la neurociencia puede preguntar qué procesos generan estas experiencias de primer orden» e intentar descubrir los correlatos neuronales del sentido de agencia de las acciones propias de uno mismo (experiencia de agencia del yo), en contraste con el sentido de que la acción pertenece a otro (agencia del otro), y ambas respecto de la experiencia de propiedad de mi propio cuerpo ${ }^{93}$.

Ahora bien, todas nuestras experiencias, también las íntimas, están radicadas en una vida corporal. Por eso, aunque hay quienes siguen comprendiendo a los seres humanos como máquinas («somos máquinas») $)^{94}$, la neurofenomenología se suma a las diversas tendencias filosóficas y científicas que convergen en la defensa de la experiencia corporal de la intimidad. En todas ellas se mantiene de alguna manera la distinción entre el cuerpo objetivable (Körper) y el cuerpo vivido (Leib), una distinción fenomenológico-hermenéutica (a mi juicio, pre-ontológica $)^{95}$ entre dos formas de «experienciar y comprender el cuerpo ${ }^{96}$.

91 VARELA, F., «Neurophenomenology: a methodological remedy to the hard problem, Journal of Consciousness Studies, 3, (1996), pp. 330-349; VArela, F., Thompson , E. y Rosch, E., The Embodied Mind: Cognitive Science and Human Experience, Cambridge, MA, MIT Press, 1991; vid. Gallagher, S. y Zahavi, D., La mente fenomenológica, pp. 68-77.

92 Gallagher, S. y Zahavi, D., La mente fenomenológica, p. 76.

93 Ibíd., p. 76.

94 Brooks, R. A., Flesh and Machines: How Robots Will Change Us, Pantheon Books, Nueva York, 2002, pp. 173-175 (citado por Shaun Gallagher y Dan Zahavi, La mente fenomenológica, p. 206).

95 Por sugerencia de Javier Gracia, para aclarar esta afirmación, remito, por ejemplo, a Ética hermenéutica (Madrid, Tecnos, 2006), donde se defiende que la filosofía ha de comenzar por una Analítica de la facticidad de la experiencia (fenomenológica, hermenéutica, genealógica y/o noológica), previa a cualquier versión ontológica del pensamiento.

96 Gallagher, S. y Zahavi, D., La mente fenomenológica, p. 209. 
Como ya vimos en el contexto de Ortega y Gasset, la experiencia primordial del cuerpo humano es la del cuerpo vivido (a diferencia del mineralizado) y es en él donde se experiencia la intimidad corporal, la vida en cada circunstancia.

La neurofenomenología abre un espacio filosófico frente a la restricción científica reduccionista, estableciendo una «unidad» entre fenomenología de la conciencia y neurobiología (explicación de cómo ocurren los procesos cerebrales en que se basa la conciencia ${ }^{97}$. El análisis de la vivencia de la intimidad muestra un «modo» especial como algo se presenta. A diferencia de la perspectiva de los computacionistas, la neurofenomenología parte también de los "agentes encarnados [embodied: corporales] y situados», por tanto, desde el punto de vista del organismo vivo en acción y sus peculiares dinamismos, sincronizados neuronalmente. Según Varela ${ }^{98}$, en la experiencia hay una unidad intrínseca de componentes reales (lo vivencial y lo neural), que no se reduce a una "correlación» de relata ya establecidos que entran en relación extrínseca, ni tampoco es aceptable interpretarla como una «relación causal» unidireccional (causalidad unidireccional), sino como una «co-determinación» o «vínculo activo». El estudio de esa unidad estructural de la experiencia es la tarea de la neuroenomenología. Pero esa unidad de co-determinación no es un mero dato, sino también una interpretación a partir de los datos científicos y los enfoques filosóficos.

Así pues, también la neurofenomenología de Varela defiende la primacía e irreductibilidad de la «experiencia vivida» corporalmente, que no ha de confundirse con la introspección. Por tanto, existe un vínculo fundamental entre el análisis filosófico (en este caso, de carácter fenomenológico) y la explicación científica (neurobiológica) de la experiencia vivida realmente (encarnada corporalmente y situada). Y, además, todo el proceso hermenéutico de interpretación entre las aportaciones de la experiencia vital y de la explicación científica está acompañado por una «vida interna» que experienciamos (sentimos experiencialmente).

\subsection{El incógnito de la intimidad y sus bases neurobiológicas}

Todavía hay quienes consideran, siguiendo la imagen del ordenador, que «somos» un «material computacional» $»^{99}$, una «red electroquímica denominada sistema nervioso», una «maquinaria», por un lado totalmente ajena a nosotros, pero que, «de algún modo, es nosotros» ${ }^{100}$. Pero se olvida así que la actividad

97 Thompson, E. and Varela, F., «Radical embodiment: neural dynamics and consciousness», Trends in Cognitive Sciences, vol. 5, 10, 2001, pp. 418-425; Esteban Vargas et alii, «Neurofenomenología del tiempo según F. Varela», Actas Españolas de Psiquiatría, 41(4), 2013, pp. 253-262.

98 VARELA, F., «Neurophenomenology: a methodological remedy to the hard problem».

99 Eagleman, D., Incógnito. Las vidas secretas del cerebro, Anagrama, Barcelona, 2013, p. 10.

$100 \quad$ Ibíd., p. 10. 
del cerebro genera también, en su interacción con el medio, «vida interior», en gran medida de modo inconsciente («de incógnito»), pero también en algunos casos conscientemente.

En realidad, «sabemos muy poco de nosotros» ${ }^{101}$ y lo que creemos saber es fruto de un proceso que no tiene carácter lógico, sino que más bien constituye una comprensión interpretadora de señales, a partir de los flujos electroquímicos a través del sistema nervioso ${ }^{102}$. Lo curioso es que esta actividad interior genera un ámbito experiencial que capacita para tener sensación de tiempo y para posponer las posibles gratificaciones, superando la debilidad de la voluntad ${ }^{103}$, es decir, lo que significa -dicho con el término clásico- la akrasía ${ }^{104}$. Un ámbito experiencial donde se llevan a cabo las negociaciones "consigo mismo» ${ }^{105}$, lo que Eagleman denomina «contratos Ulises», una figura que expresa el trato que hace uno consigo mismo entre el corto y el largo plazo de tiempo.

Ciertamente, la neurociencia contribuye a percatarnos de que la conciencia no dirige gran cantidad de «nuestras» actividades vitales. Pero el estudio del cerebro puede servir también para comprender el mundo de los «incentivos» ${ }^{106}$, porque «la gente negocia consigo misma». Se trata, al menos, de momentos de «sobria reflexión», un aspecto de la naturaleza humana, el de un «cosmos interior», que consiste en esta peculiar capacidad de hacer contratos consigo mismo, ante las tentaciones y las expectativas ${ }^{107}$.

Si queremos conocernos mejor a nosotros mismos, hemos de explorar mediante la neurobiología ese «cosmos interior», que en gran medida nos es ajeno, pero contiene los impulsos más básicos de la vida. Aunque no es aceptable afirmar que "somos nuestro cerebro y sus productos químicos», ni tampoco que somos una "red biológica» y "nada más» ${ }^{108}$. Esta visión «reduccionista» (ahora sustentada en la neurobiología) no capta adecuadamente «quién» es cada cual, ni los fenómenos vitales. La «química del cerebro» no comprende «la persona que soy», el «sí mismo» de donde proceden las decisiones. No «somos esclavos de [las] moléculas» ${ }^{109}$, porque, aunque "nuestra esencia depende (...) de nuestra biología» ${ }^{110}$, «el reduccionismo no lo es todo» ${ }^{111} \mathrm{y}$ "está condenado a decirnos muy poco acerca de las cuestiones importantes de los humanos» ${ }^{112}$. «El reduccionismo es engañoso»y "conduce a un callejón sin

\footnotetext{
101 Eagleman, D., Incógnito, p. 29.

102 Ibid., pp. 50-52.

103 Ibíd., p. 145: Eagleman alude al término «innerer Schweinhund» [cerdo interior].

104 Vid. Teruel, P. J., «Deteriora sequor. Interpretación neurofilosófica del fenómeno de la akrasía», Pensamiento (en este mismo volumen).

105 Eagleman, D., Incógnito, p. 148.

106 Ibid., p. 237.

107 Ibid., p. 238.

108 Ibid., p. 245.

109 Ibid., p. 247.

110 Ibid., p. 250

111 Ibid., p. 252.

112 Ibid., p. 253.
} 
salida» ${ }^{113}$, porque no es la mejor manera de describir y comprender a los humanos. Los mismos componentes genéticos o neuronales pueden acabar originando comportamientos destructivos o beneficiosos (por ejemplo, violencia o generosidad heroica), dependiendo del entorno. El reduccionismo no es la perspectiva adecuada para comprender la intimidad humana, dado que una explicación científica del cerebro (su física y química) no diría nada propiamente significativo de la intimidad vital. Eagleman cita, como ejemplo contra el reduccionismo, el dicho de Stuart Kaufman acerca de que una pareja de enamorados es una pareja de enamorados, no meras partículas en movimiento ${ }^{114}$.

Lo decisivo -y difícil de resolver- es comprender la experiencia de la intimidad, que emerge en y desde la realidad humana entendida como un "sistema sociobiológico». Pero lo bien cierto es el hecho de que Eagleman —como ejemplo de otros neurobiólogos- se remite continuamente a un «nosotros mismos», al «espacio interior» o "cosmos interno», a un ámbito «íntimo» que es capaz de imponer "sus propias metas, sus imperativos», porque el cerebro humano constituye un centro - una "concentración de yoidad» ${ }^{115}$-, que abre «el paisaje de nuestras vidas interiores» ${ }^{116}$.

\section{El PODER DE LA INTIMIDAD. CONFLICTO ENTRE INTIMIDAD Y REPUTACIÓN}

¿Tiene algún poder la intimidad para enfrentarse a los dinamismos de la reciprocidad y la reputación? En la vida humana será de suma importancia saber cuál es el poder de la intimidad en relación con la fuerza de la interacción con el medio y, de modo especial, con la reciprocidad y la reputación, un conflicto que puede interpretarse como la pugna entre la libertad y la socialidad humana. Recordemos la frase de Emmanuel Mounier, «se las arregla uno mejor con su mala conciencia que con su mala reputación», citada por Carlos Fuentes en su novela Las buenas conciencias de $1959^{117}$. Una frase que nos remite a Nietzsche: «Uno se acomoda más fácilmente con su mala conciencia que con su mala fama» ${ }^{118}$. Lo que pone de relieve Nietzsche es que «lo más poderoso», «lo decisivo para nuestra vida feliz», no es «lo que nosotros sabemos y recordamos de nosotros mismos», sino «lo que otros saben (o creen saber) de nosotros».

113 Ibid., pp. 260-261.

114 Ibid., p. 263. Vid. también Ayala, F. J., ¿De dónde vengo? ¿Quién soy? ¿A dónde voy?, Alianza, Madrid, 2015.

115 Ibid., p. 263.

116 Ibid., p. 271.

117 «No he tenido el valor. No he podido ser lo que quería» (Carlos Fuentes, Las buenas conciencias, Alfaguara, Madrid, 2004, p. 197). ¿He aquí la akrasía de la intimidad? (vid. Teruel, P. J., «Deteriora sequor. Interpretación neurofilosófica del fenómeno de la akrasía»).

118 Nietzsche, F., El gay saber, § 52: «Man wird mit seinem schlechtem Gewissen leichter fertig als mit seinem schlechtem Rufe». 
Ahora bien, la intimidad tendría que constituirse en un poder para orientar la acción y conformar la mismidad personal, superando tanto las diversas formas de akrasía y debilidad de la voluntad como también siendo capaz de enfrentarse al poder rival de la reputación, cuyas bases neurales también están siendo investigadas ${ }^{119}$. Se han estudiado algunos mecanismos neurales que subyacen a la toma de decisiones basadas en la reputación y que suponen dos procesos: la formación de meta-representaciones (representación de lo que otra gente piensa de nosotros) y el análisis coste-beneficio (recompensa o utilidad). Por tanto, lo que aquí está en juego es si la intimidad puede constituir una instancia crítica en correlación con el desarrollo de la conciencia moral de carácter postconvencional, por ejemplo, con el desarrollo de la conciencia de justicia, que sea capaz de superar la fuerte presión de las convenciones ${ }^{120}$; es decir, si se logra conformar un ámbito vitalmente innovador en virtud de la imaginación y la creatividad, que sea fuente de las inadaptaciones y de la libertad.

Universidad de Valencia

JESÚs CONILL

Jesus.Conill@uv.es

[Artículo aprobado para publicación en octubre de 2016]

119 Vid. Izuma, K., "The social neroscience of reputation», Neuroscience Research 72 (2012), pp. 283-288.

120 Cortina, A., "Conciencia moral y reputación. Una perspectiva neuroética», Real Academia de Ciencias Morales y Políticas, 17 de marzo de 2015; "Conciencia y reputación», El País, 22 de agosto de 2015, p. 22; y César Ortega, «¿Naturalizar la justicia? Una respuesta crítica desde la teoría moral de Jürgen Habermas»(Pensamiento, en este mismo volumen). 
